\title{
WiFi Signal Strength Degradation Over Different Building Materials
}

\author{
Aileen $^{1 *}$, Alexander Dennis Suwardi ${ }^{2}$, Fernando Prawiranata ${ }^{3}$ \\ ${ }^{1,2,3}$ Computer Science Departement, School of Computer Science, \\ Bina Nusantara University, \\ Jakarta, Indonesia 11480 \\ aileen@binus.ac.id; alexander.suwardi@binus.ac.id; fernando.prawiranata@binus.ac.id \\ *Correspondence: aileen@binus.ac.id
}

\begin{abstract}
Wireless Fidelity (WiFi) signals experience propagation through air and material in a building. This propagation causes signal decreasing signal strength. This study aims to determine materials in buildings that cause significant signal strength loss so in the future building design could factor in signal strength by using material that doesn't affect signal strength significantly. The testing of signal strength will be done by observing signal strength through different materials. Signal strength will be recorded by using a mobile app. Materials that majorly decrease signal strength are plastics, with the least affecting materials are hollow plywood wall. The use of plastics in a building affects significantly on signal loss and should be replaced if possible with hollow plywood walls.
\end{abstract}

Keywords: WiFi; Signal; Strength; Propagation; Material

\section{INTRODUCTION}

At the present time, almost all people in the world are using the internet. One way to access the internet network is through wireless signal technology such as Wireless Local Area Network (WLAN) or Wireless Fidelity (WiFi) (Suherman, S., et al., 2018).

The popularity of WiFi technology continues to increase considering the ease with which this technology is installed and utilized in everyday life. WiFi is a technology that utilizes electronic devices using radio signal waves with a specific strength based on the strength generated from the device (Henry, P., et al., 2017). With WiFi, humans can connect via the internet network without needing any cables. WiFi quality is often measured by its speed which we can measure from the strength of WiFi (Dhere, P., et al., 2018). Apart from speed, WiFi signal strength also affects the WiFi penetration rate. For example, $2.4 \mathrm{GHz}$ and $5 \mathrm{GHz}$ $\mathrm{WiFi}$, where the penetration rate of $2.4 \mathrm{GHz} \mathrm{WiFi}$ signal is higher than $5 \mathrm{GHz}$ (Own, C. M., et al., 2019).

Apart from allowing wireless connections to the internet, WiFi can also be used for other functions to facilitate human work or provide people with information that they cannot get from their senses. From day to day, researchers continue to develop models or algorithms that utilize WiFi signals in their use, such as (1) a model that can detect the type of human activity, track whether there is movement in a room, and count the number of people in a room (Depatla, S., \& Mostofi, Y., 2017; Damodaran, N., et al., 2018 ), (2) a model developed to detect human movement behind a wall (Gu, Y., Ren, F., \& Li, J., 2016; M. UmaMaheswarara, M., \& Kadaru, B. B., 2017), (3) a model to estimate a person's distance from a WiFi centre (van Engelen, J. E., et al., 2019), (4) a model to predict where the ideal location of a WiFi router is placed in a building so that it can reach the entire area with a maximum potential (Suherman, S., et al., 2018; Mathisen, A., et al., 2016), (5) models to detect dangerous objects in a suitcase without having to open the suitcase itself (Wang, C., et al., 2018). In the future, we can enjoy the improved versions of models in our daily lives.

WiFi is one technology that is often used in Smart Home; the housing mechanism that will be more common in the future (Katre, S. R., \& Rojatkar, D. V., et al., 2017). One of the implementations of WiFi in a Smart Home is the Internet of Things (IoT), which is when equipment in the home is connected wirelessly to one another via the internet. However, the equipment may be located in different rooms 
or far away. This can cause problems in catching the WiFi signal used as an intermediary for communication between the equipment. The signal that has to pass through the barrier before reaching its destination can become weaker than its original strength (van Engelen, J. E., et al., 2019). Even so, most of the problems that arise from a weak signal to an IoT device are simply that the device does not detect the signal. However, more complex problems can occur in various WiFi technology-based models that prioritize the accuracy of the captured WiFi signal strength to improve its performance. Problems that arise when these models incorrectly capture the strength of the WiFi signal can be in the form of excessive energy expenditure because they mistakenly think the signal comes from a farther location (Suherman, S., et al., 2018).

We can do several ways to increase the strength of the WiFi signal, one of which is to use an aluminium reflector that is focused in one direction (Gorade, S., et al., 2018). But it is also good if we avoid factors that can reduce the strength of WiFi signals, such as (1) human activity (Damodaran, N., et al., 2020; Thewan, T., et al, 2019), (2) electromagnetic waves (Valadares, D. C., et al., 2020), (3) magnetic fields (Wu, Y., et al., 2019), (4) distance between signal transmitter and receiver (Brinkhoff, J. \& Hornbuckle, J., 2018; Zhang, S., et al., 2018), (5) water (Mei, X. et al., 2020). (6) Obstacles such as walls, floors, ceilings, doors, or windows (Suherman, S., 2018; Suherman, S., et al., 2018; Din, Z. U., \& Bernold, L. E., 2017; Lee, H., et al., 2019; Mathisen, A., et al., 2016; Rath, H. K., et al., 2017; UmaMaheswara, M., \& Kadaru, B. B., 2017).

In buildings, there are various types of building materials that are used such as walls, floors, ceilings, doors and windows. Each type of building material has a different effect on WiFi signal propagation (Dhere, P., et al., 2018; Golubeva, T., et al., 2018; Lee, H., et al., 2019). Several researchers are also aware of this and have conducted studies to examine the impact of different building materials on the propagation rate of $\mathrm{WiFi}$ signals and other electromagnetic waves, such as a researcher who compares the strength of radio signals before and after passing through a wall or floor of a building (Din, Z. U., \& Bernold, L. E., 2017; Suherman, S., et al., 2018), or a researcher who tries to compare several building materials to find which material is the strongest to reflect electromagnetic waves (Pavlík, M., 2019). The impact of building materials on the reduction of WiFi propagation needs to be considered since designing buildings, especially buildings that want to apply models mentioned before (Lee, H., et al., 2019).

This study aims to determine the impact of certain building materials on the WiFi signal propagation by comparing the strength captured without anything blocking with the strength captured after being given a barrier in the form of building materials. This research is conducted to test other materials that have not been tested or materials that have been tested but added with new environmental conditions.

Given the use of WiFi to implement Smart Homes, which will be increasingly popular in the future, this research is expected to improve WiFi performance in Smart
Homes in the future. This study can be used to design buildings with good propagation signals or to design rooms that are free from outside signals that can interfere with inside signals. Thus, WiFi signal detection by IoT devices and WiFi coverage in buildings can be increased.

\section{METHODS}

This research was conducted using the WiFi Monitor application, an android application developed by Alexander Kozyukov and can be downloaded for free through the Google Play Store. This application is a tool that can analyze the status of the WiFi network caught by the detection device, in this case, the author's smartphone, and display data about the WiFi. These data are in the form of:

- $\quad$ name (SSID) and identifier (BSSID)

- router manufacturer

- connection speed

- $\quad$ received signal strength indication $(\mathrm{RSSI})$

- frequency

- channel width

- $\quad$ latency info (ping)

- hotspot security options

- MAC address and IP address of smartphone

- $\quad$ subnet mask, default gateway and DNS address.

From the data provided by the application above, this study will only take data of frequency and RSSI from one WiFi that is the target signal source.

\subsection{Datasets}

There will be two types of data collected whenever testing a material: (1) initial data ( $\mathrm{InD})$ : data collected before the material is placed as a barrier between the WiFi source and the smartphone; (2) final data (FiD): data collected after the material is placed as a barrier between the WiFi source and the smartphone. This method is used because the materials to be tested cannot be moved easily by the author and must be tested directly where the materials are placed. This results in the distance between the WiFi source and the smartphone will also vary in each measurement. Unfortunately, the difference in distance can affect the WiFi signal strength (SS), so it can interfere with the study's accuracy. Therefore, the authors will repeat the InD measurement at the same distance when measuring FiD each time measuring each tested material to ensure the determination of the distance variable and the accuracy of the WiFi SS change, which is only affected by the tested material.

Changes in WiFi SS will be displayed in a percentage reduction or increase in WiFi signal strength. This method was chosen considering that the WiFi SS in each InD will be different due to different distances when taking measurements. By displaying it as a percentage of subtraction or addition, the focus of data presentation will 
not be obscured by differences in WiFi SS that are affected by distance.

Parameters recorded for each tested material, both in InD and FiD, consist of data_type, material_name, material_width, frequency, channel_width, min_SS, max SS, avg_SS.

The materials that will be used as a barrier to the WiFi signal and investigated in this study are concrete floors $15 \mathrm{~cm}$ thick, wooden doors $3 \mathrm{~cm}$, hollow plywood walls 7 $\mathrm{cm}$, wooden boards $1 \mathrm{~cm}$, and plastic $0.5 \mathrm{~cm}$.

\subsection{Data Collecting}

First, the WiFi Monitor application is activated to detect the WiFi that is the research target. Second, after detecting the target $\mathrm{WiFi}$, place the smartphone in a stable and quiet place without any dynamic objects moving around to avoid unwanted interference to the WiFi signal strength. Third, wait for one minute without the slightest movement on the smartphone or objects between the smartphone and the WiFi source. During this one minute, the researcher will record the weakest signal strength and the strongest signal strength of the target WiFi captured by the smartphone. Fourth, add researched materials as a barrier between the WiFi source and the smartphone. It should be noted that the distance between WiFi and smartphone should not change to ensure the accuracy of the data. Fifth, repeat the third step in conditions with an obstacle between the WiFi source and the smartphone. These five stages will be repeated for each material to be tested.

\subsection{Data Processing}

The data collected will then be processed to calculate the percentage change in WiFi signal strength before and after being blocked by certain materials. The formula that will be used for this calculation is as follows.

The unfortunate thing about the dataset that is reachable to the author is the difference in thickness of each material. Therefore, we will look for the percentage change per $\mathrm{cm}$ to compare the effect of each material of the same thickness on the WiFi signal strength. The formula that will be used for this calculation is as follows.

\section{RESULTS AND DISCUSSION}

WiFi Monitor has a single display that displays changes in WiFi signal strength per second in the form of a line chart. When the line on the chart looks stable, the display will then be screenshotted. From the screenshot, the weakest and strongest WiFi signal strength achieved in the current state will be recorded as min_SS and max_SS. avg_SS will then be calculated by averaging the min_SS and max SS values. Data for InD and FiD collected from each material can be seen in table 1.
Tabel 1: WiFi data over different materials

\begin{tabular}{|c|c|c|c|c|c|c|}
\hline $\begin{array}{l}\text { data } \\
\text { type }\end{array}$ & $\begin{array}{c}\text { material_ } \\
\text { name }\end{array}$ & $\begin{array}{c}\text { Material } \\
\text { width } \\
\text { (cm) }\end{array}$ & $\begin{array}{l}\text { frequency } \\
\text { (Ghz) }\end{array}$ & $\begin{array}{c}\min _{-}^{-} \\
(\mathrm{dBm})\end{array}$ & $\begin{array}{c}\max _{-} \\
\mathrm{SS} \\
(\mathrm{dBm})\end{array}$ & $\begin{array}{c}\mathrm{avg}_{-} \\
\mathrm{SS} \\
(\mathrm{dBm})\end{array}$ \\
\hline InD & $\begin{array}{l}\text { Concrete } \\
\text { Floor }\end{array}$ & 15 & 2.4 & -55 & -48 & $-51,5$ \\
\hline FiD & $\begin{array}{l}\text { Concrete } \\
\text { Floor }\end{array}$ & 15 & 2.4 & -70 & -65 & -67.5 \\
\hline InD & $\begin{array}{l}\text { Wooden } \\
\text { Door }\end{array}$ & 3.4 & 2.4 & -45 & -43 & -44 \\
\hline FiD & $\begin{array}{l}\text { Wooden } \\
\text { Door }\end{array}$ & 3.4 & 2.4 & -51 & -49 & -50 \\
\hline InD & $\begin{array}{l}\text { Hollow } \\
\text { Plywood } \\
\text { Wall }\end{array}$ & 7 & 2.4 & -37 & -34 & -35.5 \\
\hline FiD & $\begin{array}{l}\text { Hollow } \\
\text { Plywood } \\
\text { Wall }\end{array}$ & 7 & 2.4 & -38 & -35 & -36.5 \\
\hline InD & $\begin{array}{l}\text { Wooden } \\
\text { Plank }\end{array}$ & 1.8 & 2.4 & -36 & -34 & -35 \\
\hline FiD & $\begin{array}{l}\text { Wooden } \\
\text { Plank }\end{array}$ & 1.8 & 2.4 & -39 & -37 & -38 \\
\hline InD & Plastic & 0.2 & 2.4 & -33 & -30 & -31.5 \\
\hline FiD & Plastic & 0.2 & 2.4 & -33 & -31 & -32 \\
\hline
\end{tabular}

The percentage change in WiFi signal strength after passing through certain materials is calculated using the methodology chapter's formula. Following that, the previous calculation results are then divided by the thickness of the material in $\mathrm{cm}$ to obtain the percentage change in WiFi signal strength after passing through a specific material as thick as $1 \mathrm{~cm}$. The calculation results for each building material can be seen in table 2 .

Tabel 2: Wifi signal strength change over different materials

\begin{tabular}{|c|c|c|}
\hline materials_name & $\begin{array}{c}\text { change__ } \\
\text { percentage }\end{array}$ & $\begin{array}{c}\text { change___cm } \\
\text { percentage_per_cm }\end{array}$ \\
\hline Concrete Floor & $-31.07 \%$ & $-2.07 \%$ \\
\hline Wooden Door & $-13.64 \%$ & $-4.01 \%$ \\
\hline Hollow Plywood Wall & $-2.82 \%$ & $-0.40 \%$ \\
\hline Wooden Plank & $-8.57 \%$ & $-4.76 \%$ \\
\hline Plastic & $-1.59 \%$ & $-7.94 \%$ \\
\hline
\end{tabular}

Figure 1 shows data visualization of change percentage ordered by materials least effect signal strength.
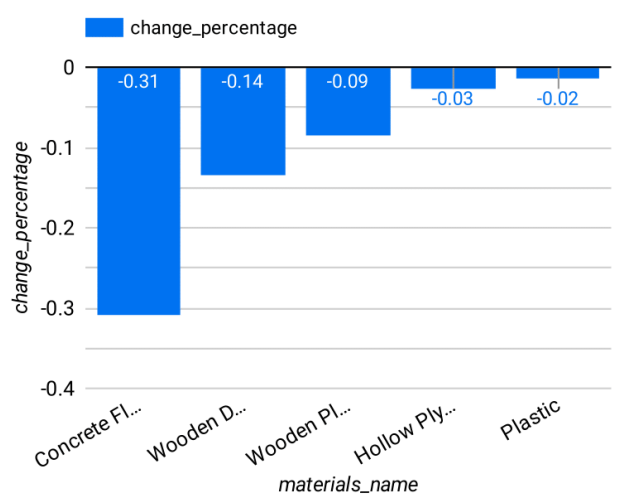

Figure 1. Percentage of WiFi signal strength change over different materials 
Figure 2 shows data visualization of change percentage_per_cm ordered by material least effect the signal strength with the same thickness.

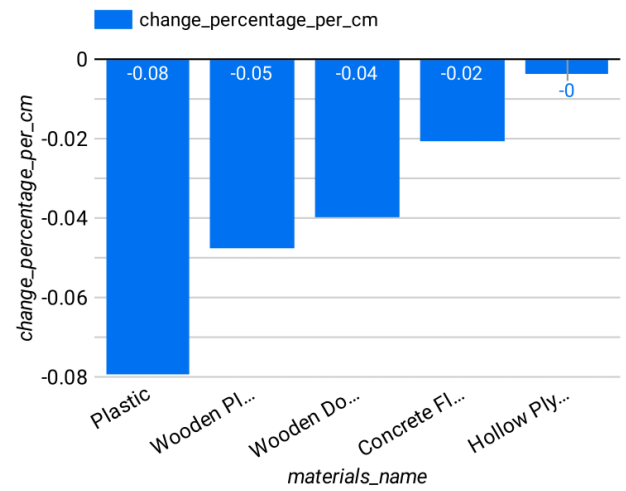

Figure 2. Percentage of WiFi signal strength change over $1 \mathrm{~cm}$ of different materials

Building materials have been proven to have a significant effect on signal strength. Many common building materials like wooden planks are dense and absorb more signal except for concrete floors, which contain steel that conducts signal as been tested in study by Suherman (Suherman, S., et al., 2018). Not only material type, thickness also affects signal strength.

From the calculation of change_percentage, we get that concrete is the material that reduces WiFi signal strength the most, while plastic is the material that has the most minor effect on WiFi signal strength. However, this result cannot be accepted as the final result because the thickness of each material is different Hence why the author decided to divide all change by material's width.

From the calculation of change_percentage_per_ $\mathrm{cm}$, we get more objective results regarding the effect of each material on the WiFi signal strength. Compared to the change percentage results, as shown in figure 2, we get the results that plastic reduces $\mathrm{WiFi}$ signal strength the most, and hollow plywood wall is the material that has a minor effect on WiFi signal strength when they have the same thickness. At a glance, this result can be considered as the final result of this research. Unfortunately, these results cannot be directly applied in real-life conditions, where the standard thickness of each material in the building is different. It is rare to find plastic with a thickness of $1 \mathrm{~cm}$, and it is almost impossible to produce usable concrete with a thickness of $1 \mathrm{~cm}$. Therefore, the authors still cannot conclude from the results of this study to answer the question of which building materials reduce the strength of the WiFi signal the most and vice versa. However, the results of this study can still be used as a reference to determine which material is the most suitable for buildings, namely by multiplying the rate of decline by the thickness of the material to be used.

\section{CONCLUSION}

Different building materials will affect different WiFi signal strength. Based on our research on six different materials, we found that plastic is the material that reduces WiFi signal strength the most when used as a barrier. On the other hand, a hollow plywood wall is the material that reduces the WiFi signal strength by the least when used as a barrier. Between them, wooden plank, wooden door, and concrete floor, ranks second, third, fourth, and fifth consecutively regarding how significant their influence on reducing WiFi signal strength is.

There is no conclusion that we can draw regarding the best building materials to increase WiFi signal strength considering the thickness standards of each material are different when used as building materials, while the results of this study only show data on materials of the same thickness.

Further research can be carried out in the future with building materials of the same thickness to obtain more accurate results in determining which material can best maintain WiFi signal strength. Future researchers can also: (1) try more diverse materials such as various metals or materials commonly used to make home furnishings; (2) try to compare the change in WiFi signal strength to a material when it is not powered compared to when it is powered by electric current.

\section{REFERENCES}

Brinkhoff, J., \& Hornbuckle, J. (2018). Characterization of WiFi signal range for agricultural WSNs. 2017 23rd Asia-Pacific Conference on Communications: Bridging the Metropolitan and the Remote, APCC 2017. IEEE. doi:10.23919/ APCC.2017.8304043

Damodaran, N., Haruni, E., Kokhkharova, M., \& Schäfer, J. (2020). Device free human activity and fall recognition using WiFi channel state information (CSI). CCF Transactions on Pervasive Computing and Interaction, 2(1), 1-17. doi:10.1007/ s42486-020-00027-1

Depatla, S., \& Mostofi, Y. (2017). Crowd counting through walls using WiFi. arXiv.

Dhere, P., Chilveri, P., Vatti, R., Iyer, V., \& Jagdale, K. (2018). Wireless Signal Strength Analysis in a Home Network. 2018 International Conference on Current Trends towards Converging Technologies (ICCTCT) (pp. 1-5). IEEE. doi:10.1109/ ICCTCT.2018.8550931

Din, Z. U., \& Bernold, L. E. (2017). Experimental study of signal behavior for wireless communication in construction. Construction Innovation, 475-491. doi:10.1108/CI-11-2016-0061

Golubeva, T., Zaitsev, Y., Konshin, S., \& Duisenbek, I. (2018). A Study on the Wi-Fi Radio Signal At- 
tenuation in Various Construction Materials (Obstacles). 2018 Tenth International Conference on Ubiquitous and Future Networks (ICUFN) (pp. 718-723). IEEE. doi:10.1109/ ICUFN.2018.8436785

Gorade, S., Vatti, R., Kaurwad, V., Bhakre, S., \& Kadam, R. (2018). Enhancement of Signal Strength of Single Antenna Wi-Fi Routers. (pp. 1-3). IEEE. doi:10.1109/ICCTCT.2018.8551077

Gu, Y., Ren, F., \& Li, J. (2016). PAWS: Passive Human Activity Recognition Based on WiFi Ambient Signals. IEEE Internet of Things Journal, 796-805. doi:10.1109/JIOT.2015.2511805

Henry, P., \& Luo, H. (2002). WiFi: what's next? IEEE Communications Magazine, 40(12), 66-72. doi:10.1109/MCOM.2002.1106162

Katre, S. R., \& Rojatkar, D. V. (2017). Home Automation: Past, Present and Future. International Research Journal of Engineering and Technology.

Lee, H., Ahn, C., Choi, N., Kim, T., \& Lee, H. (2019). The Effects of Housing Environments on the Performance of Activity-Recognition Systems Using Wi-Fi Channel State Information: An Exploratory Study. Sensors, 19(5), 983. doi:10.3390/ s19050983

Mathisen, A., Krogh Sorensen, S., Stisen, A., Blunck, H., \& Gronbaek, K. (2016). A comparative analysis of Indoor WiFi Positioning at a large building complex. 2016 International Conference on Indoor Positioning and Indoor Navigation (IPIN), (pp. 1-8). doi:10.1109/IPIN.2016.7743666

Mei, X., Wu, H., Saeed, N., Ma, T., Xian, J., \& Chen, Y. (2020). An absorption mitigation technique for received signal strength-based target localization in underwater wireless sensor networks. Sensors (Switzerland), 4698. doi:10.3390/s20174698

Musa, A., \& Paul, B. S. (2019). Impact of household construction materials on $4 \mathrm{G}$ signal. 2019 IEEE International Smart Cities Conference (ISC2) (pp. 73-78). IEEE. doi:10.1109/ ISC246665.2019.9071777

Own, C. M., Hou, J., \& Tao, W. (2019). Signal Fuse Learning Method with Dual Bands WiFi Signal Measurements in Indoor Positioning. IEEE Access, 7, 131805-131817. doi:10.1109/ACCESS.2019.2940054

PAVLÍK, M. (2019). Compare of shielding effectiveness for building materials. PRZEGLAD ELEKTROTECHNICZNY, 1(5), 139-142. doi:10.15199/48.2019.05.33

Rath, H. K., Timmadasari, S., Panigrahi, B., \& Simha, A. (2017). Realistic indoor path loss modeling for regular WiFi operations in India. arXiv.

Suherman, Fahmi, Al-Azzawi, W., Al-Akaidi, M., Sinulingga, E. P., \& Mubarakah, N. (2018). Radio-Friend- ly Building for Efficient Signal Distribution. 2018 IEEE International Conference on Communication, Networks and Satellite, Comnetsat 2018 - Proceedings, (pp. 60-63). doi:10.1109/ COMNETSAT.2018.8684092

Suherman, S. (2018). WiFi-Friendly Building to Enable WiFi Signal Indoor. Bulletin of Electrical Engineering and Informatics, 264-271. doi:10.11591/ eei.v7i2.871

Suherman, S., Mubarakah, N., Sagala, R. S., \& Prayitno, H. (2018). Wifi-friendly building, enabling wifi signal indoor: An initial study. IOP Conference Series: Earth and Environmental Science, 12-22. doi:10.1088/1755-1315/126/1/012022

Thewan, T., Seksan, C., Pramot, S., Ismail, A., \& Terashima, K. (2019). Comparing WiFi RSS Filtering for Wireless Robot Location System. Procedia Manufacturing, 143-150. doi:10.1016/j.promfg.2019.02.021

UmaMaheswararao, M., \& Kadaru, B. B. (n.d.). Seeing Through Walls Using Wi-Vi.

Valadares, D. C., Gomes, De Arajo, J. M., Rgis, F., Spohn, M. A., Perkusich, A., . . Melcher, E. U. (2020). $802.11 \mathrm{~g}$ signal strength evaluation in an industrial environment. Internet of Things, 100-163. doi:10.1016/j.iot.2020.100163

van Engelen, J. E., van Lier, J. J., Takes, F. W., \& Trautmann, H. (2019). Accurate WiFi-Based Indoor Positioning with Continuous Location Sampling. In Lecture Notes in Computer Science (including subseries Lecture Notes in Artificial Intelligence and Lecture Notes in Bioinformatics) (pp. 524540). doi:10.1007/978-3-030-10997-4_32

Wang, C., Liu, J., Chen, Y., Liu, H., \& Wang, Y. (2018). Towards In-baggage Suspicious Object Detection Using Commodity WiFi. 2018 IEEE Conference on Communications and Network Security (CNS) (pp. 1-9). IEEE. doi:10.1109/CNS.2018.8433142

Wu, Y., Wang, J., Lai, S., Zhu, X., \& Gu, W. (2019). A transparent and flexible microwave absorber covering the whole WiFi waveband. AIP Advances. doi:10.1063/1.5083102 